\title{
Atividade antifúngica de Sideroxylon obtusifolium frente a diferentes espécies de Candida sp.
}

\section{Renata Soares da Silva ${ }^{1}$, Karla Maria Santos de Oliveira ${ }^{2}$ e Giani Maria Cavalcante ${ }^{3}$}

\footnotetext{
1 Aluna de Graduação em Enfermagem do Centro Universitário Cesmac, Brasil. E-mail: renatasssilva@bol.com.br

2 Aluna de Graduação em Enfermagem do Centro Universitário Cesmac, Brasil. E-mail: karlamoliveiraenfa@yahoo.com.br

3 Doutora em Biotecnologia. Mestre em Ciências Biológicas. Bacharel e Licenciada em Ciências Biológicas. Bióloga do Instituto de Tecnologia de Pernambuco (ITEP) e Professora Doutora do Centro Universitário Mauricio de Nassau e do Centro Universitário Cesmac, Brasil. E-mail: gianimc@icloud.com
}

RESUMO: Candidiase é uma infecção fúngica oportunista cuja prevalência no mundo é de 6,9 casos por 1000 pacientes. O aumento na utilização de drogas antifúngicas, nos últimos anos, tem causado resistência aos medicamentos disponíveis para o tratamento. O objetivo deste estudo foi investigar a atividade antifúngica de Sideroxylon obtusifolium em estirpes associadas à candidiase. Os testes in vitro foram realizados com o extrato bruto e frações orgânicas contra estirpes de Candida albicans (URM 4385), Candida glabrata (URM 4264) e Candida tropicalis (URM 4262), gentilmente cedidas pela Micoteca da Universidade Federal de Pernambuco (UFPE), através do ensaio de difusão em ágar com poço e determinação da concentração inibitória mínima (CIM). O extrato etanólico e a fração metanólica das folhas S. obtusifolium apresentaram potencial antifúngico, com diâmetro dos halos de inibição variando entre 24,5$19,5 \mathrm{~mm}$ e $25,0-18,0 \mathrm{~mm}$, respectivamente, valores semelhantes à droga padrão itraconozol. Os melhores resultados de CIM foram registrados para o extrato etanólico das folhas de $S$. obtusifolium na concentração de $200 \mu \mathrm{g} / \mathrm{mL}$, com valores de CIM variando de 0,32 a 0,16 mg/mL. Estudo químico para a extração e o isolamento dos compostos ativos é recomendado para ensaios in vitro destes compostos para investigar a sua atividade antifúngica.

Palavras-chaves: Sideroxylon obtusifolium. Candidíase. Atividade antifúngica.

Antifungal activity of Sideroxylon obtusifolium against different species of Candida sp. ABSTRACT: Candidiasis is the most common and important opportunistic fungal infection with prevalence in the world is 6.9 cases per 1000 patients. The increase use of antifungal drugs in recent years, it has caused drug resistance available for the treatment. The aim of this study was investigate the antifungal activity of Sideroxylon obtusifolium against strains associated candidiasis. In vitro tests were conducted with crude extract and fractions organics against strains of Candida albicans (URM 4385), Candida glabrata (URM 4264) e Candida tropicalis (URM 4262), a courtesy of Federal University of Pernambuco (UFPE), through in agar-well diffusion assay and minimal inhibitory concentration (MIC). The extract ethanolic and fraction organic methanolic were the most active, with diameter of inhibition zones ranging between 24.5-19.5 mm and 25.0-18.0 mm, respectively, values similar to the standard drug itraconozole. The best values of MIC were to extract ethanolic in $200 \mu \mathrm{g} / \mathrm{mL}$ with values varied from 0.32 to $0.16 \mathrm{mg} / \mathrm{mL}$. Chemical study to extraction and isolation of actives compounds is recommended to in vitro assays these compounds to investigate the antimicrobial activity

Keywords: Sideroxylon obtusifolium. Candidiasis. Antifungal activity. 


\section{INTRODUÇÃO}

As espécies pertencentes ao gênero Candida são classificadas como fungos patogênicos e estão associadas a uma variedade de infecções, desde superficiais até as invasivas, que se manifestam em diferentes regiões anatômicas na espécie humana (WONG et al. 2014).

Atualmente a frequência de infecções por Candida tem aumentado substancialmente, principalmente em virtude do aumento da população de risco, que inclui pacientes transplantados, pacientes com câncer e pacientes em terapia imunossupressora (SANGUINETTI; POSTERANO; LASSFLORL, 2015). De acordo com Kent et al. (2011) a prevalência de candidemia no mundo é de 6,9 casos por 1000 pacientes, e a espécie Candida albicans é relatada como a principal espécie associada as infecções, com prevalência em $50-70 \%$ dos casos (ARENDRUP, 2010).

Segundo Pfaller, Diekema e Gibbs (2010), outras espécies de importância clínica, como Candida glabrata, Candida tropicalis, Candida parapsilosis e Candida krusei estão associadas à cerca de $90 \%$ dos casos de candidíases invasivas; enquanto, as espécies Candida guilliermondii, Candida lusitaniae, Candida kefyr, Candida famata, Candida inconspicua, Candida rugosa, Candida dubliniensis e Candida norvegensis, são relatadas com menos frequência.

Em geral, para o tratamento da candidíase, é recomendado o uso do azol fluconozol, que atua como agente fungistático com ampla atividade, entretanto, há registros de que as espécies de Candida, isoladas após o tratamento com a droga, foram as mais resistentes ao fluconozol (LORTHARY et al., 2011).
O desenvolvimento de resistência fúngica às drogas disponíveis para o tratamento de candidíase é crescente, isto em parte é devido ao uso indiscriminado de agentes antimicrobianos (MARTINS et al., 2015); e em parte, a vantagem evolutiva dos microorganismos em diminuir os riscos existentes para sua sobrevivência (FAUCl; MARSTON, 2014).

Assim, objetivando superar este problema, opções terapêuticas complementares estão sendo estudadas para reverter esse cenário de resistência apresentada pelos fungos patogênicos (PIPI et al., 2015); para isso, novas alternativas naturais e eficazes, tais como, o uso de extratos de planta, compostos naturais e semissintéticos, têm sido amplamente investigados, com vistas ao desenvolvimento de novos medicamentos (MARTINS et al., 2015).

Em virtude da relevante busca por meios terapêuticos alternativos para o tratamento de candidíase, foi investigada a atividade antifúngica de Sideroxylon obtusifolium, uma espécie vegetal pertencente à família Sapotaceae, conhecida popularmente como quixabeira, cujos registros de atividades biológicas incluem atividade antiinflamatória e antinoceptiva (ARAÚJO-NETO et al., 2010); atividade antioxidante (LEITE et al., 2015) e atividade antimicrobiana frente a Enterococcus faecalis (COSTA et al., 2010).

Embora tenham sido encontrados registros de atividade antimicrobiana para a espécie S. obtusifolium, as informações são escassas, no que concerne a investigação da atividade antifúngica, em especial para as espécies associadas à candidíase. Por conseguinte, o objetivo deste trabalho foi investigar a atividade antifúngica in vitro do extrato bruto de folhas e frações orgânicas 
de Sideroxylon obtusifolium L. frente a diferentes espécies de Candida.

\section{MATERIAIS E MÉTODOS}

A espécie vegetal foi obtida junto a Estação Experimental do Instituto Agropecuário de Pernambuco (IPA), situada na cidade de Vitória de Santo Antão, Pernambuco, em março de 2015. Diferentes partes vegetais (folha, flor, fruto e talo) foram acondicionadas em sacos plásticos individuais e levadas para confirmação e identificação da espécie por profissionais de Botânica. Uma exsicata foi depositada no Herbário do Instituto Agropecuário de Pernambuco sob $\circ \mathrm{n}^{\circ} \mathrm{I}$ PA7541.

Para a obtenção dos extratos, as folhas foram secas à temperatura ambiente e moídas com auxílio de um moinho. Seis quilos do pó foram misturados com etanol a uma concentração de $70 \%(\mathrm{v} / \mathrm{v})$ para obtenção do extrato etanólico das folhas (EEtOH). A evaporação do etanol foi realizada utilizando um evaporador rotativo sob vácuo a 30 ${ }^{\circ} \mathrm{C}$. Após evaporação do solvente, uma alíquota de $50 \mathrm{~g}$ de EEtOH foi suspensa na mistura metanol: água (1:1) e o resíduo insolúvel $(11,5 \mathrm{~g})$ foi removido por filtração. A solução hidroalcoólica foi particionada sucessivamente com hexano e acetato de etila para produzir $3,1 \mathrm{~g}$ da fração orgânica hexânica (FrHex), 10,1 g da fração orgânica acetato de etila (FrAcEOt) e 2,2 g da fração residual metanol: água (FrMeOH). Antes da utilização nos ensaios de atividade antifúngica, o extrato etanólico e as frações orgânicas foram dissolvidos em dimetilsulfóxido a $0,01 \%$ (DMSO 0,01\%) uma vez que este não interfere no desenvolvimento de microorganismos patogênicos (OSTROSKY et al., 2008).
Os micro-organismos C. albicans (URM 4385), C. glabrata (URM 4264) e C. tropicalis (URM 4262), usados nesta pesquisa, foram gentilmente cedidos pela Micoteca do Departamento de Micologia da Universidade Federal de Pernambuco (UFPE).

Todos os micro-organismos foram mantidos em meio ágar Sabouraud a uma temperatura de $4{ }^{\circ} \mathrm{C}$, até a sua utilização nos ensaios antifúngicos. Quando selecionados para os ensaios, os micro-organismos foram inoculados, com auxílio de swab, em placas de Petri contendo meio ágar Sabouraud dextrose e incubados a $37{ }^{\circ} \mathrm{C}$ por 24 horas para crescimento dos mesmos. Em seguida as suspensões foram preparadas em solução salina estéril $(\mathrm{NaCl}$ a $0,85 \%)$ e padronizadas por comparação com o tubo 1.0 da escala de MacFarland, conforme metodologia descrita por Essama et al. (2015).

Inicialmente a atividade antifúngica foi determinada por meio do ensaio de difusão em ágar (técnica de poço) como descrito por Nenaah (2013). Em placas de Petri contendo o meio ágar Sabouraud dextrose as espécies de Candida foram inoculadas, separadamente, com o auxílio de um Swab, em seguida quatro cavidades $(6 \mathrm{~mm}$ de diâmetro) foram feitas usando pipetas de Pasteur estéreis. Os poços foram saturados, separadamente, com $20 \mu \mathrm{L}$ de extrato bruto e frações orgânicas em concentrações variando de 400 a $100 \mu \mathrm{g} / \mathrm{mL}$. As placas foram incubadas a $28{ }^{\circ} \mathrm{C}$ por 48 horas. Os diâmetros das zonas de inibição foram medidos com o auxílio de uma escala milimétrica. Os testes foram realizados em duplicatas.

A determinação da Concentração Inibitória Mínima (CIM) foi realizada pelo método de microdiluição em placa de 96 poços de acordo com as normas do protocolo M27A2 do Clinical \& Laboratory Standards Insti- 
tute (CLSI, 2010). As concentrações do extrato e das frações variaram de 400-100 $\mu \mathrm{g} / \mathrm{mL}$. (ESSAMA et al., 2015). Como controles foram usados uma solução contendo 20 $\mu \mathrm{L}$ de suspensão fúngica e $80 \mu \mathrm{L}$ de meio de cultivo líquido (C1) e uma solução contendo $20 \mu \mathrm{L}$ de suspensão fúngica, $70 \mu \mathrm{L}$ de meio de cultivo líquido e $10 \mu \mathrm{L}$ do antifúngico itraconazol na concentração de $50 \mu \mathrm{g} / \mu \mathrm{L}$ (C2), conforme descrito por Anthikat et al. (2014). Em seguida, as placas foram incubadas em estufas a $37{ }^{\circ} \mathrm{C}$ por 24 horas. Após esse período foi realizada a leitura em espectrofotômetro a $595 \mathrm{~nm}$. Os testes foram realizados em triplicatas.

Os dados obtidos no ensaio de difusão em ágar por meio de poço (diâmetro de inibição) foram expressos como mé-

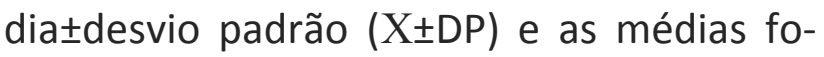
ram analisadas estatisticamente usando análise de variância (ANOVA) usando o software BioEstat versão 5.0. As diferenças foram consideradas significativas quando $p$ $\geq 0,05$.

\section{RESULTADOS E DISCUSSÃO}

Os resultados mais promissores para atividade antifúngica do extrato EEtOH e das frações orgânicas de $S$. obtusifolium frente a diferentes espécies de Candida spp. estão registrados na Tabela 1 .
Tabela 1 - Atividade antifúngica do extrato etanólico e das frações orgânicas de Sideroxylon obtusifolium frente a diferentes espécies de Candida.

Table 1 - Antifungal activity of the ethanolic extract and the organic fractions of Sideroxylon obtusifolium against different Candida species.

\begin{tabular}{|c|c|c|c|}
\hline \multirow[t]{2}{*}{ Tratamentos } & \multicolumn{3}{|c|}{ Médias da Zona de Inibição (X士DP) } \\
\hline & C. albicans & C. glabrata & C. tropicalis \\
\hline \multicolumn{4}{|l|}{ EEtOH } \\
\hline $400 \mu \mathrm{g} / \mathrm{mL}$ & $24,0 \pm 1,0^{\mathrm{a}}$ & $19,0 \pm 1,0^{a}$ & $24,5 \pm 1,0^{a}$ \\
\hline $350 \mu \mathrm{g} / \mathrm{mL}$ & $24,0 \pm 1,0^{a}$ & $19,0 \pm 0,5^{\mathrm{a}}$ & $24,5 \pm 1,0^{a}$ \\
\hline $300 \mu \mathrm{g} / \mathrm{mL}$ & $20,0 \pm 0,5^{b}$ & $18,5 \pm 1,0^{\mathrm{a}}$ & $20,0 \pm 0,5^{b}$ \\
\hline $250 \mu \mathrm{g} / \mathrm{mL}$ & $16,0 \pm 1,0^{c}$ & $13,0 \pm 1,0^{b}$ & $18,5 \pm 1,0^{c}$ \\
\hline $200 \mu \mathrm{g} / \mathrm{mL}$ & $16,0 \pm 1,0^{\mathrm{C}}$ & $8,0 \pm 0,5^{c}$ & $13,0 \pm 0,5^{d}$ \\
\hline $150 \mu \mathrm{g} / \mathrm{mL}$ & $10,0 \pm 0,5^{d}$ & NA & $7,5 \pm 1,0^{e}$ \\
\hline $100 \mu \mathrm{g} / \mathrm{mL}$ & $2,0 \pm 1,0^{\mathrm{e}}$ & NA & $5,0 \pm 1,0^{f}$ \\
\hline \multicolumn{4}{|l|}{ FrHex } \\
\hline $400 \mu \mathrm{g} / \mathrm{mL}$ & $14,0 \pm 1,0^{b}$ & $10,0 \pm 1,0^{b}$ & $14,0 \pm 1,0^{b}$ \\
\hline $350 \mu \mathrm{g} / \mathrm{mL}$ & $15,0 \pm 1,0^{b}$ & $10,5 \pm 0,5^{b}$ & $14,0 \pm 1,0^{b}$ \\
\hline $300 \mu \mathrm{g} / \mathrm{mL}$ & $10,0 \pm 0,5^{c}$ & $10,5 \pm 1,0^{b}$ & $14,0 \pm 0,5^{b}$ \\
\hline $250 \mu \mathrm{g} / \mathrm{mL}$ & $12,0 \pm 1,0^{d}$ & $5,5 \pm 1,0^{c}$ & $12,0 \pm 1,0^{c}$ \\
\hline $200 \mu \mathrm{g} / \mathrm{mL}$ & $8,0 \pm 1,0^{\mathrm{e}}$ & $1,5 \pm 0,5^{d}$ & $8,0 \pm 0,5^{d}$ \\
\hline $150 \mu \mathrm{g} / \mathrm{mL}$ & $8,0 \pm 0,5^{e}$ & NA & NA \\
\hline $100 \mu \mathrm{g} / \mathrm{mL}$ & NA & NA & NA \\
\hline \multicolumn{4}{|l|}{ FrAcEOt } \\
\hline $400 \mu \mathrm{g} / \mathrm{mL}$ & $14,0 \pm 1,0^{b}$ & $10,0 \pm 1,0^{b}$ & $15,0 \pm 1,0^{\mathrm{b}}$ \\
\hline $350 \mu \mathrm{g} / \mathrm{mL}$ & $14,0 \pm 1,0^{b}$ & $10,0 \pm 0,5^{b}$ & $15,0 \pm 0,5^{b}$ \\
\hline $300 \mu \mathrm{g} / \mathrm{mL}$ & $14,0 \pm 0,5^{b}$ & $10,0 \pm 1,0^{b}$ & $15,0 \pm 1,0^{b}$ \\
\hline $250 \mu \mathrm{g} / \mathrm{mL}$ & $13,0 \pm 1,0^{c}$ & $12,0 \pm 1,0^{c}$ & $11,0 \pm 1,0^{c}$ \\
\hline $200 \mu \mathrm{g} / \mathrm{mL}$ & $10,0 \pm 1,0^{d}$ & $11,5 \pm 0,5^{c}$ & $10,5 \pm 0,5^{c}$ \\
\hline $150 \mu \mathrm{g} / \mathrm{mL}$ & $10,0 \pm 0,5^{d}$ & $8,0 \pm 0,5^{d}$ & $5,0 \pm 0,5^{d}$ \\
\hline $100 \mu \mathrm{g} / \mathrm{mL}$ & $8,0 \pm 1,0^{\mathrm{e}}$ & $4,5 \pm 1,0^{\mathrm{e}}$ & $3,5 \pm 1,0^{\mathrm{e}}$ \\
\hline \multicolumn{4}{|l|}{ FrMeOH } \\
\hline $400 \mu \mathrm{g} / \mathrm{mL}$ & $25,0 \pm 1,0^{a}$ & $18,5 \pm 1,0^{\mathrm{a}}$ & $24,0 \pm 1,0^{\mathrm{a}}$ \\
\hline $350 \mu \mathrm{g} / \mathrm{mL}$ & $25,0 \pm 1,0^{a}$ & $18,5 \pm 0,5^{a}$ & $24,0 \pm 1,0^{a}$ \\
\hline $300 \mu \mathrm{g} / \mathrm{mL}$ & $24,5 \pm 0,5^{a}$ & $18,0 \pm 1,0^{a}$ & $23,5 \pm 0,5^{a}$ \\
\hline $250 \mu \mathrm{g} / \mathrm{mL}$ & $12,0 \pm 1,0^{b}$ & $15,0 \pm 1,0^{b}$ & $19,5 \pm 1,0^{b}$ \\
\hline $200 \mu \mathrm{g} / \mathrm{mL}$ & $11,0 \pm 1,0^{b}$ & $13,5 \pm 0,5^{b}$ & $15,0 \pm 0,5^{c}$ \\
\hline $150 \mu \mathrm{g} / \mathrm{mL}$ & $8,0 \pm 0,5^{c}$ & $9,0 \pm 0,5^{c}$ & $10,5 \pm 1,0^{d}$ \\
\hline $100 \mu \mathrm{g} / \mathrm{mL}$ & $5,0 \pm 1,0^{d}$ & $9,0 \pm 0,5^{c}$ & $8,0 \pm 1,0^{\mathrm{e}}$ \\
\hline C1 & NA & NA & NA \\
\hline C2 & $25,0 \pm 0,5^{a}$ & $19,5 \pm 0,5^{\mathrm{a}}$ & $25,0 \pm 0,5^{a}$ \\
\hline
\end{tabular}

$\mathrm{NA}=$ não ativo. Na mesma coluna, médias seguidas de letras iguais não diferem estatisticamente em si $(p \leq 0,05)$. EBF (Extrato bruto da folha); FrHex (Fração Hexânica); FrAcEOt (Fração Acetato); FrMeOH (Fração Metanólica); C1 (Controle 1: $20 \mu \mathrm{L}$ de suspensão fúngica $+80 \mu \mathrm{L}$ de meio de cultivo líquido); $\mathrm{C} 2$ (Controle 2: $20 \mu \mathrm{L}$ de suspensão fúngica $+70 \mu \mathrm{L}$ de meio de cultivo líquido $+10 \mu \mathrm{L}$ do antifúngico itraconazol [50 $\mu \mathrm{g} / \mu \mathrm{L}]$ ).

No ranking mundial de infeç̧ões fúngicas associadas às doenças de base, as espécies do gênero Candida estão classificadas como a quarta maior causadoras de infecções e com registros de altos índices de mortalidade por infecções nosocomiais, comparáveis 
com espécies bacterianas do gênero Pseudomonas spp. e superior a espécie bacteriana Staphylococcus aureus (HIDRON et al., 2008; WISPLINGHOFF et al., 2004).

De acordo com Ghannoum e Rice (1999), o último século testemunhou um aumento significativo da prevalência de resistência a agentes antifúngicos que teve implicações importantes de morbidade, mortalidade e nos custos de cuidados de saúde.

Neste contexto a busca por novos agentes antimicrobianos tem aumentado substancialmente, e neste cenário as substâncias de origem natural ganham destaque, em virtude do seu potencial terapêutico, explorado e desvendado dia-a-dia, com efetivas descobertas de novos compostos eficazes na prevenção e tratamento de doenças infecciosas.

Nesta pesquisa o extrato etanólico (EE$\mathrm{tOH}$ ) das folhas de S. obtusifolium se apresentou com potencial antifúngico promissor frente às espécies $C$. albicans, $C$. glabrata $e$ C. tropicalis no que concerne a inibição do crescimento, com valores entre 24,5 e 19,5 $\mathrm{mm}$, do halo de inibição. Dentre as frações orgânicas testadas, a fração metanólica foi a que apresentou os melhores resultados para inibição do crescimento fúngico, com os valores do halo de inibição variando entre 25,0 e $18,0 \mathrm{~mm}$. Esses valores obtidos para inibição do crescimento das espécies C. albicans, C. glabrata e C. tropicalis, pelo extrato etanólico e pela fração metanólica, são semelhantes ao controle do fármaco padrão, utilizado para inibir o crescimento fúngico.

Os resultados obtidos neste trabalho refutam os obtidos por Costa et al. (2013) que investigou a atividade antifúngica dos extratos brutos de casca de caule de S. obtusifolium frente as espécies C. kruzei, C. albicans,
C. glabrata e C. tropicalis e não registrou inibição no crescimento. De acordo com Maciel, Pinto e Vieira-Junior (2002), as plantas contêm inúmeros constituintes e seus extratos, quando testados, podem apresentar diferentes princípios ativos devido a presença de compostos de classes ou estruturas, que variam quanto a concentração e quanto a localização no vegetal.

Kuete et al. (2006) e Ezuruike et al. (2015), registraram atividade antifúngica significativa frente às espécies $C$. kruzei, $C$. albicans, C. tropicalis dos extratos de Tridesmostenom omphalocarpoides e Pachystela brevipes, espécies pertencentes a família Sapotaceae. A quimiotaxonomia assegura que espécies pertencentes a um mesmo gênero ou família apresentam as mesmas classes químicas de substâncias (MACIEL; PINTO; VIEIRA-JUNIOR, 2002). Considerando essa afirmativa, os resultados obtidos nesse trabalho apontam uma potencial atividade antifúngica do extrato etanólico das folhas de S. obtusifolium, bem como da sua fração metanólica, frente às espécies $C$. kruzei, C. albicans, C. glabrata e C. tropicalis, uma vez que os dados obtidos estão condizentes com aqueles registrados pelos autores Kuete et al. (2006) e Ezuruike et al. (2015).

De acordo com Michelin et al. (2005) a concentração inibitória mínima (CIM) é a menor concentração capaz de inibir o crescimento de micro-organismos. Os menores resultados de CIM foram registrados para o extrato etanólico das folhas de S. obtusifolium na concentração de $200 \mu \mathrm{g} / \mathrm{mL}$, com valores de CIM variando de 0,32 a 0,16 $\mathrm{mg} / \mathrm{mL}$ para todas as espécies fúngicas testadas (Tabela 2).

Os resultados obtidos estão próximos aos obtidos por Martins et al. (2015), que 
registraram valores de CIM iguais a 0,15 $\mathrm{mg} / \mathrm{mL}$ em ensaios de atividade antimicrobiana frente as espécies fúngicas $C$. albicans, C. glabrata e C. tropicalis, utilizando plantas com indicação de uso medicinal.

Não foram encontrados trabalhos que apontem a menor concentração de extrato de S. obtusifolium necessário para inibir o crescimento das espécies estudadas nesta pesquisa, o que dificulta o confronto de dados para esse parâmetro.

Tabela 2 - Concentração Inibitória Mínima (CIM) do extrato etanólico e das frações orgânicas de Sideroxylon obtusifolium $(200 \mathrm{\mu g} / \mathrm{mL})$ frente a diferentes espécies de Candida.

Table - 2 Inhibitory Minimal Concentration (MIC) of the ethanolic extract and the organic fractions of Sideroxylon obtusifolium $(200 \mu \mathrm{g} / \mathrm{mL})$ against different Candida species.

\begin{tabular}{ccc}
\hline Cepa & Tratamentos & $\mathrm{CIM}(\mathrm{mg} / \mathrm{mL})$ \\
\hline & EEtOH & 0,16 \\
C. albicans (URM 4385) & FrHex & NA \\
& FrAcEOt & NA \\
& FrMeOH & 0,40 \\
& $\mathrm{C} 1$ & NA \\
& $\mathrm{C} 2$ & 0,125 \\
\hline & & \\
C. glabrata (URM 4264) & EEtOH & 0,16 \\
& FrHex & NA \\
& FrAcEOt & NA \\
& FrMeOH & 0,40 \\
& $\mathrm{C1}$ & $\mathrm{NA}$ \\
& $\mathrm{C2}$ & 0,5 \\
\hline & EEtOH & 0,32 \\
& FrHex & $\mathrm{NA}$ \\
C. tropicalis (URM 4262) & FrAcEOt & $\mathrm{NA}$ \\
& FrMeOH & 0,32 \\
& $\mathrm{C} 1$ & $\mathrm{NA}$ \\
& $\mathrm{C2}$ & 0,5 \\
\hline
\end{tabular}

NA = Não ativo. EBF (Extrato bruto da folha); FrHex (Fração Hexânica); FrAcEOt (Fração Acetato); FrMeOH (Fração Metanólica); $\mathrm{C} 1$ (Controle 1: $20 \mu \mathrm{L}$ de suspensão fúngica $+80 \mu \mathrm{L}$ de meio de cultivo líquido); C2 (Controle 2: $20 \mu \mathrm{L}$ de suspensão fúngica $+70 \mu \mathrm{L}$ de meio de cultivo líquido $+10 \mu \mathrm{L}$ do antifúngico itraconazol $[50 \mu \mathrm{g} / \mu \mathrm{L}])$.

\section{CONCLUSÃO}

Por meio deste estudo foi possível concluir que o extrato etanólico e a fração orgânica metanólica das folhas de S. obtusifolium apresentaram potencial antifúngico promissor, frente às espécies fúngicas $C$. albicans, C. glabrata e C. tropicalis. Em virtude dos resultados promissores, é sugestivo o estudo químico detalhado da espécie S. obtusifolium para isolamento de substâncias químicas; bem como, a utilização destas substâncias em ensaio in vitro frente a espécies de cândidas acima citadas e outras espécies fúngicas associadas à candidíase.

\section{REFERÊNCIAS}

ANTHIKAT, R. R. N. et al. Antifungal activity of Areca catechu L. International Journal of Pharmaceutical and Clinic Science, $v, 4, n$, 1, p.1-3, 2014.

ARAÚJO-NETO, V. et al. Therapeutic benefits of Sideroxylon obtusifolium (Humb. Ex Roem \& Schult) T. D. Penn., Sapotaceae, in experimental models of pain and inflammation. Revista Brasileira de Farmacognosia, v.20, n.6, p.933-938, 2010.

ARENDRUP, M . C. Epidemiology of invasive candidiasis. Current Opinion Critical Care, v.16, n.1, p.445-452, 2010.

CLINICAL \& LABORATORY STANDARDS INSTITUTE (CLSI). Reference method for broth dilution antifungal susceptibility testing of yeasts, Approved Standard M27-A2, 2nd ed. Disponível em: <http://clsi.org/>. Acesso em: 19 jun. 2017.

COSTA, E. M. B. et al. In vitro antimicrobial activity of plant extracts of semi-arid region of Paraiba, PB, Brazil. Journal of Dental Science, v.28, n.4, p.101-104, 2013.

COSTA, E. M. M. B. et al. Estudo in vitro da ação antimicrobiana de extratos de plantas contra Enterococcus faecalis. Jornal Brasileiro de Patologia e Medicina Laboratorial, v.46, n.3, p.175-180, 2010.

EZURUIKE, I. T. et al. Isolation, characterization and antibacterial evaluation of zymos- 
terol from the root of Pachystela brevipes (Sapotaceae). Scholars Academic Journal of Pharmacy, v.4, n.1, p.35-41, 2015.

ESSAMA, S. H. R. et al. In vitro evaluation of the antifungal activity of extracts of Baillonella toxisperma (Pierre), a sapotaceae, on the grownth of some noman pathogenic yeasts. African Journal of Pharmacy and Pharmacology, v.9, n.9, p. 99-306, 2015. FAUCl, A.; MARSTON, $H$. The perpetual challenge of antimicrobial resistance. Journal of the American Medical Association, v.311, n.18, p.1853-1854, 2014.

GHANNOUM, M. A.; RICE, L. B. Antifungal activity agents: mode of action, mechanism of resistance, and correlation of these mechanisms with bacterial resistance. Clinical Microbiology Reviews, v. 12, n.4, p.501517, 1999.

HIDRON, A.I.; et al. National healthcare safety network team; participating national healthcare safety network facilities. NHSN annual update: antimicrobial-resistant pathogens associated with healthcareassociated infections: annual summary of data reported to the National Healthcare Safety Network at the Centers for Disease Control and Prevention, 2006-2007. Infect. Control Hospital Epidemiology, v.29, n.12, p.9961011, 2008.

KENT, D. H. et al. Candida blood-stream infections in intensive care units: analysis of the extended prevalence of infection in intensive care unit study. Critic Care Medicinal, v.39, n.2, p.665-670, 2011.

KUETE, V. et al. Antimicrobial activity of the methanolic extract from the stem bark of Tridesmostenom omphalocarpoides (Sapotaceae). Journal of Ethnopharmacology, v.104, n.3, p.5-11, 2006.

LEITE, N.S.; LIMA, A.P.; ARAÚJO-NETO, V.; ESTEVAM, C.S.; PANTALEÃO, S.M.; CAMAR-
GO, E.A.; FERNANDES, R.P.M.; COSTA, S.K.P.; MUSCARÁ, M.N.; THOMAZZI, S.M. Avaliação das atividades cicatrizante, antiinflamatória tópica e antioxidante do extrato etanólico da Sideroxylon obtusifolium (quixabeira). Revista Brasileira de Plantas Medicinais, v, 17, n.1, p.164-170, 2015.

LORTHOLARY, O. et al. Recent exposures to caspofungin or fluconazole influences are epidemiology of candidemia: A prospective multicenter study involving 2.M41 patterns. Antimicrobial Agents Chemotherapy, v. 55, n. 2, p.532-538, 2011.

MACIEL, M. A. M.; PINTO, A. C.; VEIGA-JR, V. F. Plantas medicinais: a necessidade de estudos multidisciplinares. Química Nova, v. 25, n. 3, p.429-438, 2002.

MARTINS, N. et al. Plants used in folk medicine: the potential of their hydromethanolic extracts agaisnt candida species. Industrial Crops and Product, v.66, n.2, p.62-67, 2015. MICHELIN, D. C. et al. Avaliação da atividade antimicrobiana de extratos vegetais. Revista Brasileira de Farmacognosia, v. 15, n. 2, p. 316-320, 2005.

NENAAH G. Antimicrobial activity of Calotropis procera Ait (Asclepiadaceae) and isolation of four flavonoid glycosides as the active constituents. World Journal Microbiology Biotechnology, v.29, n.1, p.12551262, 2013.

OSTROSKY, E. A., et al. Métodos para avaliação da atividade antimicrobiana e determinação da concentração inibitória mínima (CIM) de plantas medicinais. Brazilian Journal of Pharmacognosy, v.18, n.2, p. 301307, 2008.

PFALLER, M. A.; DIEKEMA, D. J.; GIBBS, D. L. Results from the artemis disk global antifungal surveillance study: 1997 to 2007: a 10.5-year analysis of susceptibilities of candida species to fluconazole and voriconazo- 
le as determined by CLSI standardized disk diffusion. Journal Clinical Microbiology, v.48, n.2, p. 1366-1377, 2010.

PIPI, B. et al. In vitro evaluation of the acquisition of resistance, antifungal activity and synergism of Brazilian red propolis with antifungal drugs on Candida ssp. Journal Applied Microbiology, v.118, n.3, p. 839850, 2015.

SANGUINETI, M.; POSTERANO, B.; LASSFLORL, C. Antifungal drug resistance among Candida species: mechanism and clinical impact. Mycoses, v.58, n.2, p.2-13, 2015.

WISPLINGHOFF, $\mathrm{H}$. et al. Nosocomial bloodstream infections in US hospitals: analysis of 24,179 cases from a prospective nationwide surveillance study. 2004. Clinical. Infection Diseases, v.39, n.1, p.309 -317, 2004.

WONG, S. S. W. et al. In vitro activity of a novel antifungal small molecule against candida infections. Plos One, v.2, n. 2, p.2132, 2014.

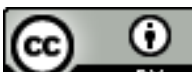

License information: This is an openaccess article distributed under the terms of the Creative Commons Attribution License, which permits unrestricted use, distribution, and reproduction in any medium, provided the original work is properly cited.

Artigo recebido em 03 de agosto de 2017.

Avaliado em 09 de agosto de 2017.

Aceito em 15 de agosto de 2017.

Publicado em 18 de agosto de 2017.

\section{Como citar este artigo (ABNT):}

SILVA, Renata Soares da; OLIVEIRA, Karla Maria Santos de; CAVALCANTE, Giani Maria. Atividade antifúngica de Sideroxylon obtusifolium frente a diferentes espécies de Candida sp. Estação Científica (UNIFAP), Macapá, v. 7, n. 1, p. 95-102, jan./abr. 2017. 